\title{
Gas Evolution in Lithium-Ion Batteries: Solid versus Liquid Electrolyte
}

Florian Strauss,,${ }^{\dagger, \star}$ Jun Hao Teo,${ }^{\dagger}$ Alexander Schiele,${ }^{\dagger}$ Timo Bartsch, ${ }^{\dagger}$ Toru Hatsukade,${ }^{\dagger}$ Pascal Hartmann, ${ }^{\dagger, \neq}$ Jürgen Janek, ${ }^{\dagger, \S}$ and Torsten Brezesinski ${ }^{\dagger, *}$

† Battery and Electrochemistry Laboratory, Institute of Nanotechnology, Karlsruhe Institute of Technology (KIT), Hermann-von-Helmholtz-Platz 1, 76344 EggensteinLeopoldshafen, Germany.

‡ BASF SE, Carl-Bosch-Strasse 38, 67056 Ludwigshafen, Germany.

$\S$ Institute of Physical Chemistry \& Center for Materials Science, Justus-LiebigUniversity Giessen, Heinrich-Buff-Ring 17, 35392 Giessen, Germany.

\begin{abstract}
Gas evolution in conventional lithium-ion batteries using Ni-rich layered oxide cathode materials presents a serious issue, responsible for performance decay and safety concerns, among others. Recent findings revealed gas evolution occurring also in bulktype solid-state batteries. To further clarify the effect that the electrolyte has on gassing, we report in this work-to the best of our knowledge-the first study comparing gas evolution in lithium-ion batteries with NCM622 cathode material and different electrolyte types, specifically solid ( $\beta$ - $\mathrm{Li}_{3} \mathrm{PS}_{4}$ and $\mathrm{Li}_{6} \mathrm{PS}{ }_{5} \mathrm{Cl}$ ) versus liquid (LP57). Using isotopic labeling, acid titration, and in situ gas analysis, we show the presence of $\mathrm{O}_{2}$ and $\mathrm{CO}_{2}$ evolution in both systems, albeit with different cumulative amounts, and possible $\mathrm{SO}_{2}$ evolution for the lithium thiophosphate-based cells. Our results demonstrate the importance of considering gas evolution in solid-state batteries, especially the formation and release of highly corrosive $\mathrm{SO}_{2}$, due to side reactions with the electrolyte.
\end{abstract}

\section{Keywords}

Lithium-ion battery, all-solid-state battery, organic carbonate liquid electrolyte, lithium thiophosphate solid electrolyte, gas evolution, interfacial chemistry

\section{TOC Graphic}

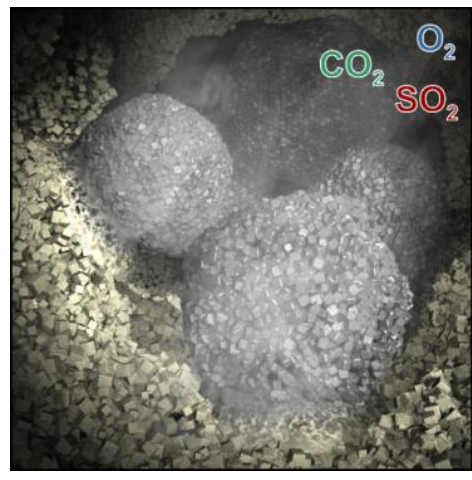




\section{Introduction}

Lithium-ion batteries (LIBs) are an indispensable energy storage technology nowadays, enabling the widespread use of portable electronics. In addition, and even more importantly, LIBs are key to the efforts toward transportation electrification. ${ }^{1}$ State-of-the-art LIBs rely on layered lithium transition metal oxides as cathode, such as $\mathrm{Li}_{1+x}\left(\mathrm{Ni}_{1-y-z} \mathrm{Co}_{y} \mathrm{Mn}_{z}\right)_{1-x} \mathrm{O}_{2}(\mathrm{NCM})$, and graphite as anode in combination with an organic carbonate-based liquid electrolyte.

Increasing the fraction of redox-active $\mathrm{Ni}$ in NCM-type cathode materials has been shown a viable strategy for achieving specific capacities of $\geq 200 \mathrm{mAh} / \mathrm{g}_{\mathrm{NCM}}$ in a reasonable voltage range. ${ }^{2}$ However, the operation of such NCMs in liquid electrolytebased LIBs (referred to as liq-LIBs in the following) causes the formation of gaseous side products, such as $\mathrm{O}_{2}, \mathrm{CO}$, and $\mathrm{CO}_{2}$, among others, eventually leading to performance loss and safety issues. ${ }^{3-5}$

Various possible pathways of gas generation have been discussed in literature. ${ }^{4-9}$ Firstly, the electrochemical oxidation of the organic electrolyte gives rise to $\mathrm{CO}$ and $\mathrm{CO}_{2}$ evolution. ${ }^{6}$ Secondly, the electrochemical decomposition of residual carbonate species, usually present on the surface of especially Ni-rich $\mathrm{NCMs}$, leads to $\mathrm{CO}_{2}$ and $\mathrm{O}_{2}$ evolution, predominantly in the initial charge cycle. ${ }^{9}$ Thirdly, the structural instability of Ni-rich NCMs at high states of charge (SOC) causes the release of lattice $\mathrm{O}_{2}$, which chemically reacts with the liquid electrolyte, thereby producing $\mathrm{CO}$ and $\mathrm{CO}_{2}{ }^{5,8}$

As we have shown recently for bulk-type solid-state batteries (SSBs), similar gas evolution can also occur, along with unique $\mathrm{SO}_{2}$ formation, when using lithium thiophosphate solid electrolytes. ${ }^{10,11}$ Nevertheless, the effect of different thiophosphates on gas evolution is yet to be studied as well as how it compares to liqLIBs. In this work, we present a comparative study to clarify such questions, focusing on the evolution of $\mathrm{CO}_{2}$ and $\mathrm{O}_{2}$ in liq-LIB and $\mathrm{SSB}$ cells and $\mathrm{SO}_{2}$ in the latter using isotopic labeling combined with in situ gas analysis.

\section{Experimental}

\section{Materials Preparation}

For the synthesis of $\beta-\mathrm{Li}_{3} \mathrm{PS}_{4}$ solid electrolyte, stoichiometric amounts of $\mathrm{Li}_{2} \mathrm{~S}$ (Sigma Aldrich; 99+\%) and $\mathrm{P}_{2} \mathrm{~S}_{5}$ (Sigma Aldrich; 99\%) in a $70 \mathrm{~mL}$ zirconia jar with 10-mmdiameter zirconia balls ( 55:1 ball-to-powder ratio) were mixed under argon for $1 \mathrm{~h}$ at $250 \mathrm{rpm}$. Then, the mixing speed was increased to $650 \mathrm{rpm}$, and the milling was continued for $20 \mathrm{~h}$. The resultant powder material had a conductivity of $\sim 0.5 \mathrm{mS} / \mathrm{cm}$.

For the synthesis of $\mathrm{Li}_{6} \mathrm{PS}_{5} \mathrm{Cl}$ solid electrolyte, $\mathrm{Li}_{2} \mathrm{~S}, \mathrm{P}_{2} \mathrm{~S}_{5}$, and $\mathrm{LiCl}$ (Alfa Aesar; 99+\%) in a $250 \mathrm{~mL}$ zirconia jar with 10-mm-diameter zirconia balls were milled under argon for $1 \mathrm{~h}$ at $250 \mathrm{rpm}$ and then for $20 \mathrm{~h}$ at $450 \mathrm{rpm}$. Subsequently, the harvested material was heated for $5 \mathrm{~h}$ at $300{ }^{\circ} \mathrm{C}$ in a vacuum. Note that (i) the ball-to-powder ratio was $\sim 27: 1$, (ii) $\mathrm{LiCl}$ was predried overnight at $300^{\circ} \mathrm{C}$ in a vacuum, and (iii) $\mathrm{Li} 2 \mathrm{~S}$ was used in a less than stoichiometric amount (by $10 \mathrm{~mol} . \%$ ). The resultant powder material had a conductivity of $\sim 2.0 \mathrm{mS} / \mathrm{cm}$. 


\section{Regeneration of Cathode Material}

$\mathrm{Li}_{1+x}\left(\mathrm{Ni}_{0.6} \mathrm{Co}_{0.2 \mathrm{Mn}} \mathrm{M}_{2}\right){ }_{1-x} \mathrm{O}_{2}(\mathrm{NCM} 622,60 \% \mathrm{Ni})$ cathode material (BASF SE; $D_{\mathrm{V}}^{50}=5.19$ $\mu \mathrm{m}, D_{\mathrm{V}}^{90}=9.04 \mu \mathrm{m}$ ) was heated in oxygen flow for $2 \mathrm{~h}$ at $740^{\circ} \mathrm{C}$ to remove both native $\mathrm{LiOH}$ and $\mathrm{Li}_{2} \mathrm{CO}_{3}$ surface contaminants. The resultant powder material was stored under argon for further use. ${ }^{3-5}$

\section{$\mathrm{Li}_{2}{ }^{13} \mathrm{CO}_{3}$ Surface Layer Formation}

For the formation of $\mathrm{Li}_{2}{ }^{13} \mathrm{CO}_{3}$ on the cathode material's surface, regenerated (i.e., virtually $\mathrm{Li}_{2} \mathrm{CO}_{3}$-free) $\mathrm{NCM} 622$ was placed in a custom cell under a $\sim 2.5 \mathrm{bar}{ }^{13} \mathrm{C}$-labeled $\mathrm{CO}_{2}$ atmosphere (Sigma Aldrich; 99 at. $\%{ }^{13} \mathrm{C}$ ). ${ }^{12}$ The storage cell underwent purge cycles following its assembly to replace the initial argon atmosphere. In addition, 300 $\mu \mathrm{L}$ of $\mathrm{H}_{2} \mathrm{O}$ was introduced into a cavity inside of the cell to accelerate the carbonate formation. Finally, it was placed in an oven for $2 \mathrm{~h}$ at $60^{\circ} \mathrm{C}$.

\section{SSB Cell Assembly and Testing}

All steps were performed under argon. The cathode composite was prepared in a 70 $\mathrm{mL}$ zirconia jar with 10-mm-diameter zirconia balls ( 30:1 ball-to-powder ratio) by mixing either $\beta-\mathrm{Li}_{3} \mathrm{PS}_{4}$ or $\mathrm{Li}_{6} \mathrm{PS}_{5} \mathrm{Cl}$ solid electrolyte, NCM622 cathode material, and Super C65 carbon black additive (Timcal) in a 3:7:0.1 weight ratio for 30 min at 140 $\mathrm{rpm}$. The SSB cells were assembled in a 10-mm-diameter PEEK ring, its use ensuring relatively high pressures to be applied onto the pellet without cracking or relaxation occurring. The ring was placed on a steel mold, allowing the powder to be sequentially pressed into pellets. First, $100 \mathrm{mg}$ of solid electrolyte were compacted at $\sim 125 \mathrm{MPa}$. Next, $13 \mathrm{mg}$ of cathode composite $\left(11-12 \mathrm{mgNCM} / \mathrm{cm}^{2}, \sim 2.1 \mathrm{mAh} / \mathrm{cm}^{2}\right)$ were pressed by hand onto the solid electrolyte layer. Then, an 8-mm-diameter Al mesh was carefully placed onto the cathode composite, followed by compression at $440 \mathrm{MPa}$. In addition, a 9-mm-diameter stainless steel mesh was placed onto the Al mesh/cathode layer to help promote connectivity. Subsequently, the PEEK ring was removed from the steel mold along with the solid electrolyte separator and cathode composite layers. Finally, a 100- $\mu \mathrm{m}$-thick, 8-mm-diameter In anode (Alfa Aesar) was attached to the pellet, and the PEEK ring containing the assembled cell (with spacers on both sides) was introduced into the differential electrochemical mass spectrometry (DEMS) setup. The cathode spacer had 1-mm-diameter holes to ensure proper outflow of released gas during cycling. All SSB cycling [after leaving the cell at open circuit voltage (OCV) for $6 \mathrm{~h}$ ] was done at a $\mathrm{C} / 20$ rate, with $1 \mathrm{C}=180 \mathrm{~mA} / \mathrm{gNCM}$, and at $45^{\circ} \mathrm{C}$ in the potential range between 2.3 and $4.4 \mathrm{~V}$ versus In/InLi using a BioLogic VMP potentiostat.

\section{Separating Solid Electrolyte and Cathode Material}

To determine the carbonate content of the SSB cathode composite after mixing and after the initial cycle, the solid electrolyte had to be removed, as the strong $\mathrm{H}_{2} \mathrm{~S}$ evolution when using the acid titration setup (more details below) did not allow for accurate measurement of $\mathrm{CO}_{2}$. Hence, $\sim 30 \mathrm{mg}$ of either cathode composite or cycled 
SSB pellet were dispersed in $3 \mathrm{~mL}$ of $\mathrm{N}$-methylformamide (Sigma Aldrich; NMF), able to dissolve the solid electrolyte while leaving $\mathrm{Li}_{2} \mathrm{CO}_{3}$ unaffected. The In anode was removed in the case of the cycled SSB pellet before dissolving in NMF. The NMF was carefully dried over activated molecular sieves (Merck); the $\mathrm{H}_{2} \mathrm{O}$ content was determined to be $\sim 2 \mathrm{ppm}$ by Karl-Fischer titration. After pouring of the solution and repeated washing with NMF, the powder was dried for at least $24 \mathrm{~h}$ in a vacuum prior to acid titration measurement. The NCM622 cathode material with an artificially grown $\mathrm{Li}_{2}{ }^{13} \mathrm{CO}_{3}$ surface layer served as reference sample and was treated in the same way as described above (to ensure the carbonate is not affected by the NMF).

\section{Liq-LIB Cell Assembly and Testing}

Electrodes were prepared with a composition of 94 wt.\% NCM622 cathode material, 3 wt.\% Solef5130 polyvinylidene fluoride binder (Solvay), and 1 wt.\% Super C65 carbon black and 2 wt.\% SFG6L graphite additives (Timcal). The areal loading was $\sim 8.5$ $\mathrm{mgNcm} / \mathrm{cm}^{2}$. For DEMS, the liq-LIB cells were assembled inside an Ar-filled glovebox by stacking 600- $\mu \mathrm{m}$-thick, 32-mm-diameter Li anode (Albemarle Germany $\mathrm{GmbH}$ ), 36mm-diameter Celgard 2500 polypropylene separator, and 30-mm-diameter NCM622 cathode. The latter electrode had $4 \mathrm{~mm}$ diameter holes in the middle for proper gas extraction and attachment of a Li reference electrode. $260 \mu \mathrm{L}$ of LP57 (BASF SE; $1 \mathrm{M}$ $\mathrm{LiPF}_{6}$ in $3: 7$ by weight ethylene carbonate and ethyl methyl carbonate) was used as electrolyte. The cells were left at OCV for $6 \mathrm{~h}$ and then cycled at a $\mathrm{C} / 10$ rate (higher compared with the SSB cells due to experimental constraints), with $1 \mathrm{C}=240 \mathrm{~mA} / \mathrm{gNCM}$, and at $45^{\circ} \mathrm{C}$ with a charge capacity limitation of $240 \mathrm{mAh} / \mathrm{gNCM}$. The cutoff potential on discharge was set to $3.0 \mathrm{~V}$ versus $\mathrm{Li}^{+} / \mathrm{Li}$.

\section{Gas Characterization}

The gas evolution was studied using DEMS by monitoring $m / z=1-100$. Helium (purity $6.0,2.5 \mathrm{~mL} / \mathrm{min}$ ) served as carrier gas for both the SSB and liq-LIB cells. The extracted gas was analyzed by a mass spectrometer (Pfeiffer Vacuum GmbH; OmniStar GSD 320). Additional information is provided in literature. ${ }^{13,14}$

\section{Carbonate Determination}

4-11 mg of NCM622 powder was introduced into a vial with a septum-sealed cap. Next, $1 \mathrm{M} \mathrm{H}_{2} \mathrm{SO}_{4}$ (Merck KGaA), degassed for $1 \mathrm{~h}$ through argon bubbling, was added. The reaction between $\mathrm{Li}_{2} \mathrm{CO}_{3}$ and $\mathrm{H}_{2} \mathrm{SO}_{4}$ releases $\mathrm{CO}_{2}$, which was extracted from the vial using argon carrier gas (purity 6.0), controlled by a mass flow controller (Bronkhorst High-Tech BV; EL-FLOW Select) at $2.5 \mathrm{~mL} / \mathrm{min}$. The evolution of both ${ }^{12} \mathrm{CO}_{2}$ and ${ }^{13} \mathrm{CO}_{2}$ was monitored quantitatively by a mass spectrometer (Pfeiffer Vacuum $\mathrm{GmbH}$; HiCube Pro with a PrismaPlus detector). 


\section{Results and Discussion}

As mentioned previously, NCM622 $(60 \% \mathrm{Ni})$ was used in this study as cathode material. To unequivocally prove the nature of evolved gasses, the native carbonate surface contaminants were first removed through $2 \mathrm{~h}$ treatment at $740^{\circ} \mathrm{C}$ in flowing $\mathrm{O}_{2}$, and then they were regrown in a controlled manner using isotopically pure ${ }^{13} \mathrm{CO}_{2}$. After drying the NCM622 overnight at $300^{\circ} \mathrm{C}$ in a vacuum, acid titration coupled with mass spectrometry was carried out to determine the amount of carbonate species. The resultant $\mathrm{Li}_{2}{ }^{12} \mathrm{CO}_{3}$ and $\mathrm{Li}_{2}{ }^{13} \mathrm{CO}_{3}$ contents were 0.07 and 0.76 wt.\%, respectively, corresponding to $\sim 92 \%{ }^{13} \mathrm{C}$.
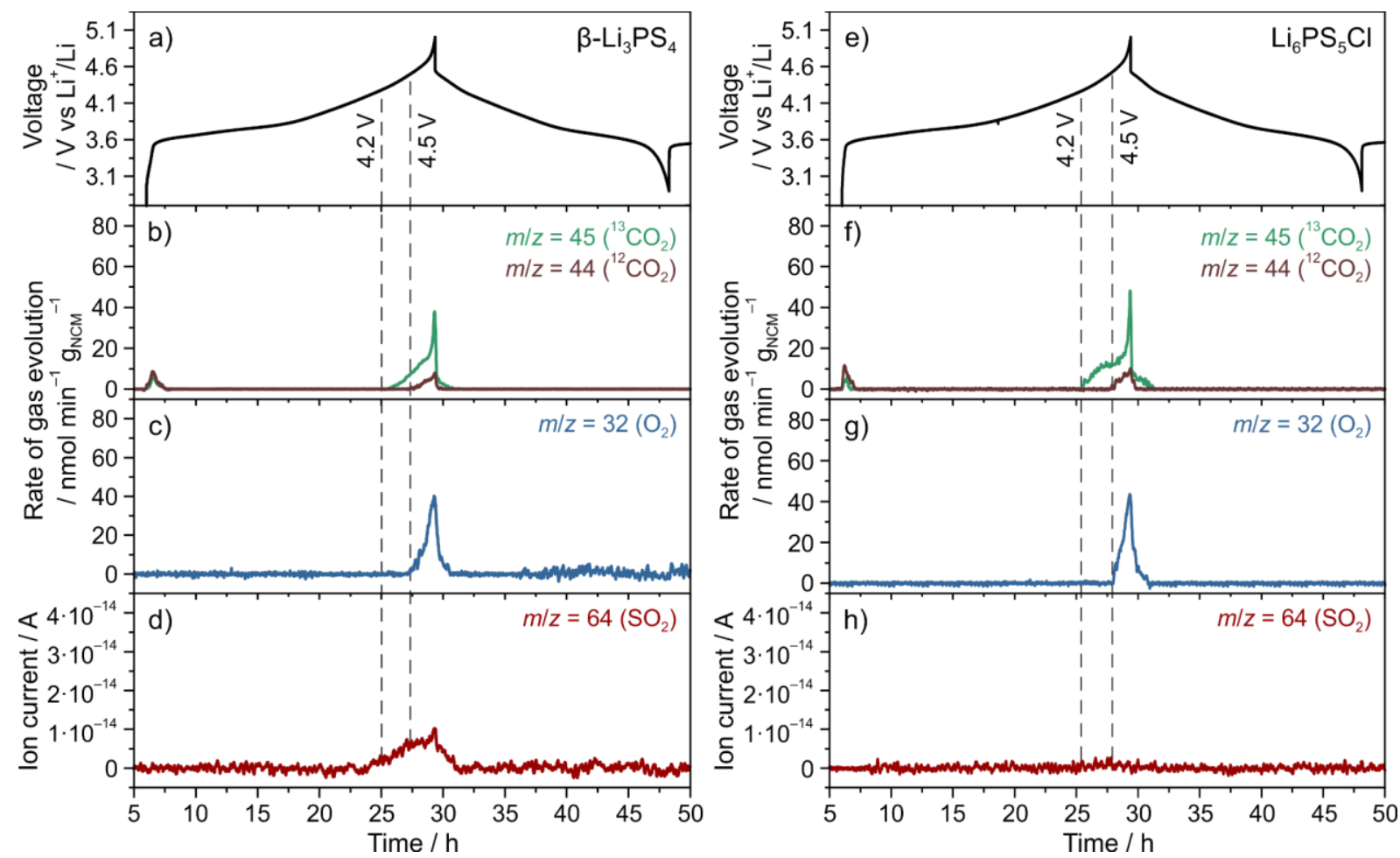

Figure 1. Electrochemical trace of SSB cells using (a) $\beta$ - $\mathrm{Li}_{3} \mathrm{PS} S_{4}$ and (e) $\mathrm{Li}_{6} \mathrm{PS} \mathrm{PS}_{5} \mathrm{Cl}$ solid electrolyte and the corresponding time-resolved $(b, f){ }^{12} \mathrm{CO}_{2},{ }^{13} \mathrm{CO}_{2}$ and $(\mathrm{c}, \mathrm{g}) \mathrm{O}_{2}$ evolution rates and $(\mathrm{d}, \mathrm{h})$ ion current for $\mathrm{SO}_{2}$. The cells were cycled in the potential range of 2.3-4.4 $\mathrm{V}$ with respect to $\mathrm{In} / \mathrm{InLi}\left(\sim 2.9-5.0 \mathrm{~V} \mathrm{vs} \mathrm{Li}^{+} / \mathrm{Li}\right)$.

Next, SSB and liq-LIB cells were assembled, and the gas evolution in the initial cycle was monitored using DEMS (mass signals from $m / z=1-100$ ). The setup employed is described in some more detail in literature. ${ }^{10,13,14}$ In a first step, SSB cells with $\beta$-Li3 $\mathrm{PS}_{4}$, NCM622, and In as solid electrolyte, cathode, and anode, respectively, were examined. They were cycled at a rate of $\mathrm{C} / 20$ and $45^{\circ} \mathrm{C}$ between 2.3 and $4.4 \mathrm{~V}$ versus $\mathrm{In} / \mathrm{InLi}$, corresponding to $\sim 2.9-5.0 \mathrm{~V}$ with respect to $\mathrm{Li}^{+} / \mathrm{Li}$. As is evident from Figure 1a, the electrochemical trace is characteristic of Ni-rich NCM, with first cycle specific charge and discharge capacities of 210 and $170 \mathrm{mAh} / \mathrm{g}_{\mathrm{NCM}}$. Regarding gas evolution, two signals with $\mathrm{m} / \mathrm{z}=44$ and 45 , referring to ${ }^{12} \mathrm{CO}_{2}$ and ${ }^{13} \mathrm{CO}_{2}$, respectively, were clearly visible near the end of the charge cycle (Figure 1b). The ${ }^{13} \mathrm{CO}_{2}$ evolution can be attributed to the electrochemical decomposition of $\mathrm{Li}_{2}{ }^{13} \mathrm{CO}_{3}$ on the $\mathrm{NCM} 622$ surface, the onset being $\sim 4.2 \mathrm{~V}$ versus $\mathrm{Li}^{+} / \mathrm{Li}$, in agreement with literature. ${ }^{5,9,15}$ However, the 
onset of ${ }^{12} \mathrm{CO}_{2}$ evolution was $\sim 300 \mathrm{mV}$ higher in potential compared with that of ${ }^{13} \mathrm{CO}_{2}$. An explanation might be that the native carbonate contaminants can only be partially removed from the NCM622 secondary particles during the regeneration process, especially those that are present in the interior of the material. At high potentials or SOC, the particles typically undergo some fracture, which may release ${ }^{12} \mathrm{CO}_{2}$. However, oxidation of Super C65 carbon black additive, present in the cathode composite, cannot be excluded.

Minor $\mathrm{CO}_{2}$ formation was also observed in the beginning of the initial charge cycle, probably because of side reactions occurring at the interface of In anode and solid electrolyte separator. This hypothesis relies on the fact that the $\mathrm{CO}_{2}$ onset potential is strongly correlated with that of $\mathrm{H}_{2}(\mathrm{~m} / \mathrm{z}=2)$, the latter of which appears as a sharp peak (Figure S1). $\mathrm{H}_{2}$ evolution may be related to trace $\mathrm{H}_{2} \mathrm{O}$ reduction in the cell. ${ }^{6,10}$ However, we believe that it is also associated with the solid electrolyte and the released $\mathrm{H}_{2}$ is capable of somewhat reacting with the carbonate species, thereby forming $\mathrm{CO}_{2} .{ }^{16}$ In addition, the onset potentials of ${ }^{12} \mathrm{CO}_{2}$ and ${ }^{13} \mathrm{CO}_{2}$ evolution (in the beginning of charging) were found to be identical within the experimental error, arguing for a chemical rather than an electrochemical reaction. In this context, it should be noted that no $\mathrm{H}_{2} \mathrm{~S}(\mathrm{~m} / \mathrm{z}=34)$ evolution was detected, suggesting either complete removal of trace $\mathrm{H}_{2} \mathrm{O}$ during the initial reduction or insensitivity of the solid electrolyte to very low levels of $\mathrm{H}_{2} \mathrm{O}$ (Figure S1). In any case, the lack of $\mathrm{H}_{2} \mathrm{~S}$ evolution indicates that $\mathrm{H}_{2} \mathrm{O}$ related effects are negligible in these experiments.

Moreover, a sharp peak for $m / z=32$, referring to $\mathrm{O}_{2}$, was visible at the end of charge, the onset potential being $\sim 4.5 \mathrm{~V}$ versus $\mathrm{Li}^{+} / \mathrm{Li}$ (Figure 1c). The $\mathrm{O}_{2}$ evolution can originate from two different sources as proposed in literature, either its release from the NCM lattice or the electrochemical decomposition of $\mathrm{Li}_{2} \mathrm{CO}_{3}$ (note that for the $\mathrm{Li}_{6} \mathrm{PS}_{5} \mathrm{Cl}$-based SSB cells, the apparent molar ratio of $\mathrm{CO}_{2}: \mathrm{O}_{2}$ is of the order of 2:1 expected for the latter reaction). ${ }^{9,15,17}$ Both sources seem reasonable here. However, the release of $\mathrm{O}_{2}$ from the NCM lattice requires the SOC to be $\geq 80 \%$ (100\% refers to full delithiation). ${ }^{17}$ The initial specific charge capacity was $210 \mathrm{mAh} / \mathrm{gNCM}_{\mathrm{N}}$, which is equivalent to $\sim 76 \%$ SOC. Hence, one would not expect to observe any $\mathrm{O}_{2}$ evolution. Nevertheless, as demonstrated recently for SSBs, inhomogeneities in SOC may be present during cycling. In other words, occurrence of cathode material fractions possessing different $\mathrm{SOC}$ is possible, ${ }^{18-20}$ and thus some of the NCM622 particles may exceed $80 \%$ SOC, eventually leading to $\mathrm{O}_{2}$ loss.

Lastly, a trace for $\mathrm{m} / \mathrm{z}=64\left(\mathrm{SO}_{2}\right)$ was observed (Figure 1d), a unique feature that has been reported so far only for SSB cells using $\beta$-Li ${ }_{3} \mathrm{PS}_{4}$ solid electrolyte. ${ }^{10,11}$ The most obvious route leading to $\mathrm{SO}_{2}$ formation and release is the reaction between $\mathrm{O}_{2}$ and the solid electrolyte, accompanied by formal sulfur oxidation, along with the formation of solid oxygenated sulfur and phosphorus species as confirmed by X-ray photoelectron spectroscopy (XPS) and time-of-flight secondary ion mass spectrometry (ToF-SIMS), among others. ${ }^{21-24}$ As mentioned above, two sources of $\mathrm{O}_{2}$ are generally possible, namely $\mathrm{O}_{2}$ released from the NCM lattice or through the electrochemical decomposition of $\mathrm{Li}_{2} \mathrm{CO}_{3}$. Having in mind that the evolved $\mathrm{O}_{2}$ during cycling appears to be partially or completely highly reactive ${ }^{1} \mathrm{O}_{2},{ }^{15,25,26}$ a gas/solid reaction may even occur 
at $45{ }^{\circ} \mathrm{C}$, despite a recent report that surface oxidation of lithium thiophosphates (by ${ }^{3} \mathrm{O}_{2}$ ) requires much higher temperatures. ${ }^{27}$ The DEMS data, especially the result that the $\mathrm{SO}_{2}$ evolution begins/stops simultaneously with the ${ }^{13} \mathrm{CO}_{2}$ evolution (during charge and discharge at $\sim 4.2 \mathrm{~V}$ vs $\mathrm{Li}^{+} / \mathrm{Li}$ ), support such reaction mechanism.

Given the apparent effect of lithium thiophosphate solid electrolytes on the gassing behavior, we subsequently substituted $\beta-\mathrm{Li}_{3} \mathrm{PS}_{4}$ for argyrodite $\mathrm{Li}_{6} \mathrm{PS}{ }_{5} \mathrm{Cl}$ in an otherwise identical SSB. Cycling of such cells under the same conditions resulted in gas evolution characteristics of ${ }^{12} \mathrm{CO}_{2},{ }^{13} \mathrm{CO}_{2}$, and $\mathrm{O}_{2}$ (Figure 1e-g), similar to those for $\beta-\mathrm{Li}_{3} \mathrm{PS}_{4}$. However, a clear distinction was observed for $\mathrm{SO}_{2}$ (Figure 1h). In contrast to $\beta-\mathrm{Li}_{3} \mathrm{PS}_{4}$, there was no $\mathrm{SO}_{2}$ evolution, thereby suggesting higher chemical stability of $\mathrm{Li}_{6} \mathrm{PS} \mathrm{S}_{5} \mathrm{Cl}$ toward reaction with ${ }^{1} \mathrm{O}_{2}$ and/or formation of only solid decomposition products. Note that its lower electrochemical stability does not necessarily affect the gas evolution. 28,29 In all cases of $\mathrm{Li}_{6} \mathrm{PS}{ }_{5} \mathrm{Cl}$ samples, $\mathrm{SO}_{2}$ peaks in the raw data were indistinguishable from the background. Moreover, if any peaks were observed, the ion current was usually much lower compared with the $\beta$-Li $\mathrm{i}_{3} \mathrm{PS}_{4}$ samples and they did not correspond to the timeframe where other characteristic gasses $\left(\mathrm{CO}_{2}\right.$ and $\left.\mathrm{O}_{2}\right)$ evolved. For both types of SSB cells, the evolution of gases detected during the initial cycle was also seen for the second and third cycles, although with decreased intensity (Figures S2 and $\mathbf{S 3}$ ).

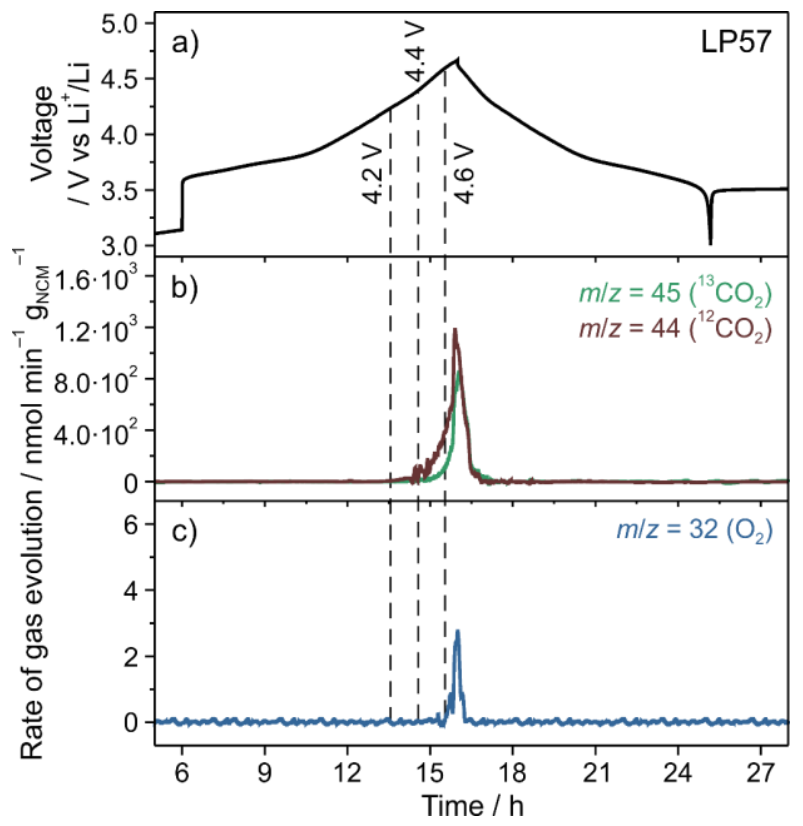

Figure 2. (a) Electrochemical trace of a liq-LIB cell cycled using a charge capacity limitation of $240 \mathrm{mAh} / \mathrm{g}_{\mathrm{NCM}}$ and the corresponding time-resolved $(\mathrm{b}){ }^{12} \mathrm{CO}_{2},{ }^{13} \mathrm{CO}_{2}$ and (c) $\mathrm{O}_{2}$ evolution rates.

Thus far, we have shown that gas evolution related to $\mathrm{CO}_{2}, \mathrm{O}_{2}$, and partially $\mathrm{SO}_{2}$ occurs in battery cells depending on the electrolyte used. To compare gassing in such systems in a more detailed manner, conventional liq-LIBs using tape-cast electrodes with the same NCM622 cathode material and LP57 electrolyte were assembled. The cells were cycled at a rate of $\mathrm{C} / 10$ and $45^{\circ} \mathrm{C}$ with a charge capacity limitation of $240 \mathrm{mAh} / \mathrm{gNCM}$ $(\sim 87 \%$ SOC). The voltage profile is displayed in Figure $\mathbf{2 a}$. As shown in Figure $\mathbf{2 b}$, 
both ${ }^{12} \mathrm{CO}_{2}$ and ${ }^{13} \mathrm{CO}_{2}$ evolution at the end of charge/beginning of discharge can be spotted, with onset potentials of $\sim 4.2$ and $\sim 4.4 \mathrm{~V}$ versus $\mathrm{Li}^{+} / \mathrm{Li}$, respectively. This result indicates that decomposition of LP57 electrolyte occurs prior to $\mathrm{Li}_{2} \mathrm{CO}_{3}$ decomposition, in agreement with literature. ${ }^{5,17}$ At first sight, in contrast to the SSB cells, the quantity of evolved ${ }^{12} \mathrm{CO}_{2}$ seems greater than that of ${ }^{13} \mathrm{CO}_{2}$, which can be attributed to the additional contribution from the (electro)chemical decomposition of the carbonatebased liquid electrolyte, accounting for ${ }^{12} \mathrm{CO}_{2}$ formation (note that, because of the isotopic labeling, $\mathrm{Li}_{2} \mathrm{CO}_{3}$ decomposition is mainly responsible for ${ }^{13} \mathrm{CO}_{2}$ evolution). ${ }^{5,9,30}$ Moreover, in line with previous literature reports, $\mathrm{O}_{2}$ evolution arises at an onset potential of $\sim 4.6 \mathrm{~V}$ versus $\mathrm{Li}^{+} / \mathrm{Li}$ (Figure 2c), referring to $\sim 83 \%$ SOC. ${ }^{17}$ We also observed $\mathrm{H}_{2}$ and $\mathrm{CO}$ evolution (Figure S4), typically originating from the reductive decomposition of the liquid electrolyte and/or trace water. ${ }^{6}$ However, with their maximum amplitude occurring near the end of charge, it is more likely that these are stemming from oxidative electrolyte decomposition processes, with $\mathrm{CO}$ being a direct product ${ }^{12,17}$ and $\mathrm{H}_{2}$ an indirect product, arising from the reduction of protic species that are formed at the positive electrode and diffuse to the negative electrode. ${ }^{6}$ The apparent time-shift between the peaks of $\mathrm{CO}$ and $\mathrm{H}_{2}$ (with $\mathrm{H}_{2}$ evolving slightly later than $\mathrm{CO}$ ) supports this hypothesis.

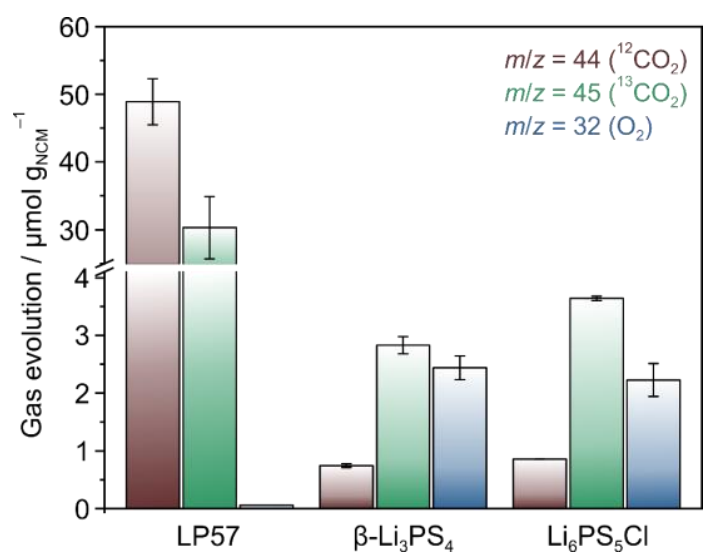

Figure 3. Total quantity of ${ }^{12} \mathrm{CO}_{2},{ }^{13} \mathrm{CO}_{2}$, and $\mathrm{O}_{2}$ evolved during the initial charge/discharge cycle at $45{ }^{\circ} \mathrm{C}$ of SSB and liq-LIB cells. Error bars indicate the standard deviation of two independent measurements.

Because the SSB and liq-LIB cells show common $\mathrm{CO}_{2}$ and $\mathrm{O}_{2}$ evolution, the total quantity of evolved gases in the initial cycle can be compared (Figure 3). Note that the liq-LIBs were charged using a specific capacity limitation of $240 \mathrm{mAh} / \mathrm{gNCM}_{\mathrm{N}}$ to achieve a similar SOC to the SSBs. Although the latter cells showed slightly lower specific capacities, ranging from 210 to $230 \mathrm{mAh} / \mathrm{gNCM}$, inhomogeneities in SOC of the NCM622 particles, especially for pelletized SSB cells, are inevitable, ${ }^{18-20}$ warranting such comparison.

First of all, in the case of the LP57 electrolyte, the ${ }^{12} \mathrm{CO}_{2}$ amount was significantly larger $\left(\sim 49 \mu \mathrm{mol} / \mathrm{gNCM}_{\mathrm{N}}\right)$, compared to $\sim 1 \mu \mathrm{mol} / \mathrm{g}_{\mathrm{NCM}}$ for the SSB cells. As mentioned above, this is because of decomposition of the carbonate-based liquid electrolyte, mainly contributing to ${ }^{12} \mathrm{CO}_{2}$ formation. As the carbonate surface species were labeled with ${ }^{13} \mathrm{C},{ }^{13} \mathrm{CO}_{2}$ evolution can be attributed unambiguously to the electrochemical 
decomposition of $\mathrm{Li}_{2} \mathrm{CO}_{3}$. For the liq-LIB cells, about an order of magnitude more ${ }^{13} \mathrm{CO}_{2}$ evolved compared with the SSB cells $\left(\sim 30\right.$ vs $\left.3-4 \mu \mathrm{mol} / \mathrm{gNCM}_{\mathrm{N}}\right)$. We suspect that this difference is due to (i) better ionic and electronic percolation in the liq-LIB electrode and/or (ii) trapping of $\mathrm{CO}_{2}$ by the solid electrolyte (pore blocking or physisorption/chemisorption) and/or (iii) formation of solid side products in the case of the SSB cells. The fraction of ${ }^{12} \mathrm{CO}_{2}$ to the total quantity of evolved $\mathrm{CO}_{2}\left[{ }^{12} \mathrm{C} /\left({ }^{12} \mathrm{C}+{ }^{13} \mathrm{C}\right)\right]$ was $\sim 0.08$ in the pristine ${ }^{13} \mathrm{C}$-labeled $\mathrm{NCM} 622$ (from acid titration measurements). However, for the first cycle gas evolution, it was much larger than expected at $\sim 0.18$ (from DEMS measurements). The reason is unclear at present but may be related to the unique surface structure and/or partial oxidation of Super C65 carbon black in the SSB cathode composites.

Moreover, the amount of released $\mathrm{O}_{2}$ was similar for the different SSB cells $(\sim 2$ $\mu \mathrm{mol} / \mathrm{gNCM}_{\mathrm{N}}$ ). For the liq-LIB cells, it was more than an order of magnitude lower. Nevertheless, in the case of the LP57 electrolyte, the virtually total consumption of released $\mathrm{O}_{2}$ through side reactions with the carbonate liquid electrolyte, leading to ${ }^{12} \mathrm{CO}_{2}$ and $\mathrm{CO}$ formation, among others, must be taken into account. ${ }^{17,30}$ Note that such phenomenon is also responsible for the occasional absence of the $\mathrm{O}_{2}$ signal (below the detection limit). Similar reactions seem to occur for the SSB cells. This means that part of the released ${ }^{1} \mathrm{O}_{2}$ undergoes follow-up reactions, either leading to formation of $\mathrm{SO}_{2}$ or solid products as mentioned above, however, not as pronounced as for the liqLIB cells because gas/liquid reactions tend to be kinetically favored over gas/solid reactions.

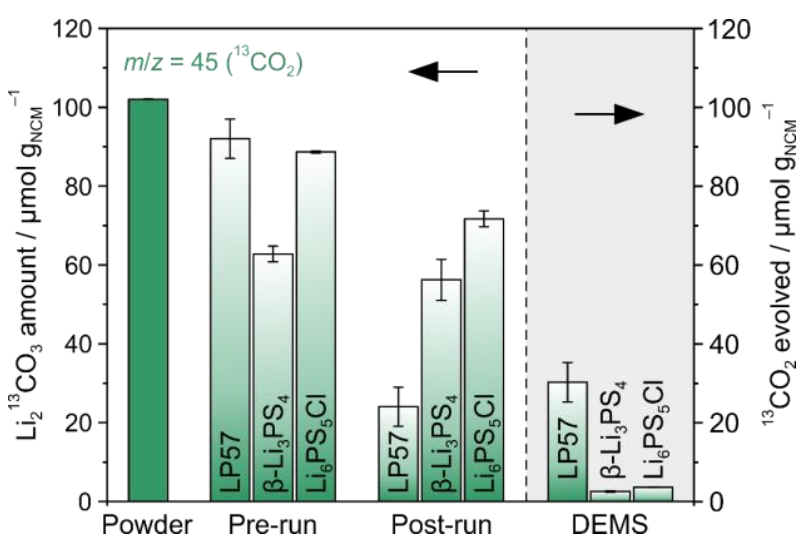

Figure 4. Amount of $\mathrm{Li}_{2}{ }^{13} \mathrm{CO}_{3}$ on the $\mathrm{NCM} 622$ cathode material before and after cycling from acid titration measurements compared to the cumulative amount of ${ }^{13} \mathrm{CO}_{2}$ from DEMS. Error bars indicate the standard deviation of two independent measurements.

$\mathrm{Li}_{2} \mathrm{CO}_{3}$ contaminants on Ni-rich and $\mathrm{Li} / \mathrm{Mn}$-rich cathode materials have been recognized lately to account for $\mathrm{CO}_{2}$ evolution, especially during the initial cycle of liqLIBs, and also to be responsible for ${ }^{1} \mathrm{O}_{2}$ formation. ${ }^{9,12,15}$ Both to further clarify the role of such surface residuals in the $\mathrm{CO}_{2}$ release and to identify unique characteristics for the SSB cells, we quantitatively determined the amount of $\mathrm{Li}_{2} \mathrm{CO}_{3}$ present on the NCM622 cathode material by acid titration measurements prior to and after cycling (Figure 4 and Table S1) and compared this with the DEMS results. We only focus on ${ }^{13} \mathrm{CO}_{2}$, as ${ }^{13} \mathrm{C}$ is the major species within the surface layer after tailored formation of 
$\mathrm{Li}_{2}{ }^{13} \mathrm{CO}_{3}$, and thus can be considered representative for the carbonate contaminants in this case. The amount of artificially grown $\mathrm{Li}_{2}{ }^{13} \mathrm{CO}_{3}$ on the NCM622 particles was determined to be $\sim 102 \mu \mathrm{mol} / \mathrm{gNCM}$. After electrode preparation (referred to as pre-run), this initial value was strongly decreased to $\sim 63 \mu \mathrm{mol} / \mathrm{gNCM}_{\mathrm{No}}$ for $\beta$-Lis $\mathrm{PS}_{4}$ and slightly decreased to $\sim 89$ and $\sim 92 \mu \mathrm{mol} / \mathrm{gNCM}$ for $\mathrm{Li}_{6} \mathrm{PS} \mathrm{S}_{5} \mathrm{Cl}$ and the tape-cast electrodes used in the liq-LIB cells, respectively. This implies that some of the carbonate species on the NCM622 surface react with the $\beta$-Li $\mathrm{i}_{3} \mathrm{PS}_{4}$ solid electrolyte during preparation of the cathode composite, forming gaseous and/or solid side products. However, their nature remains elusive at present. After the initial cycle (referred to as post-run), a further reduction in $\mathrm{Li}_{2}{ }^{13} \mathrm{CO}_{3}$ amount, because of electrochemical decomposition, was observed in all cases. Note that chemical decomposition due to reaction with HF, for example, is also feasible for the liq-LIB cells. In particular, it diminished to $\sim 56, \sim 72$, and $\sim 24 \mu \mathrm{mol} / \mathrm{gNCM}_{\mathrm{NC}}$ for $\beta$ - $\mathrm{Li}_{3} \mathrm{PS}_{4}, \mathrm{Li}_{6} \mathrm{PS}{ }_{5} \mathrm{Cl}$, and $\mathrm{LP} 57$ electrolyte, respectively. This foremost suggests higher connectivity between the NCM622 particles and the electrolyte in the liq-LIB cells (i.e., better electrochemical addressability of the active material and therefore $\mathrm{Li}_{2}{ }^{13} \mathrm{CO}_{3}$ ), which does not come as a surprise though, as inhomogeneities pertaining to inactive (electrically isolated) cathode material in pelletized SSB cells have been reported. ${ }^{18-20}$ Moreover, this observation is in line with recent reports that most of the carbonate surface species are decomposed during the initial cycle for liq-LIBs. ${ }^{9,12}$

Adding up the total quantity of evolved ${ }^{13} \mathrm{CO}_{2}$ from DEMS and the amount of $\mathrm{Li}_{2}{ }^{13} \mathrm{CO}_{3}$ deduced from acid titration measurements after the initial cycle (post-run) should yield a similar amount of $\mathrm{Li}_{2}{ }^{13} \mathrm{CO}_{3}$ to that obtained for the as-prepared cathodes (pre-run). However, there are apparent discrepancies, ranging from $<15 \%$ for $\beta-\mathrm{Li}_{3} \mathrm{PS}_{4}$ and $\mathrm{Li}_{6} \mathrm{PS}_{5} \mathrm{Cl}$ to $\sim 40 \%$ for the LP57 electrolyte. Such discrepancies are probably because of differences in reactivity of the electrolytes tested and/or partial solubility of $\mathrm{CO}_{2}$ in the case of the liquid electrolyte. In addition, the altered local environment of ${ }^{13} \mathrm{C}$ in the tape-cast electrodes, resulting from the presence of graphite additive and polyvinylidene difluoride binder, may also play a role.

\section{Conclusions}

In summary, we have shown common $\mathrm{CO}_{2}$ and $\mathrm{O}_{2}$ evolution upon cycling of LIB cells using a Ni-rich layered oxide cathode material (NCM622) and either a liquid (LP57) or solid electrolyte $\left(\beta-\mathrm{Li}_{3} \mathrm{PS}_{4}\right.$ or $\left.\mathrm{Li}_{6} \mathrm{PS} \mathrm{S}_{5} \mathrm{Cl}\right)$. Both species originate from the electrochemical decomposition of $\mathrm{Li}_{2} \mathrm{CO}_{3}$ surface contaminants and/or $\mathrm{O}_{2}$ release from the NCM lattice at high SOC. Oxidative decomposition of the liquid electrolyte also contributes to $\mathrm{CO}_{2}$ evolution in the liq-LIB cells, amounting to a significant share of the total quantity of evolved gases. From a numbers perspective, the cumulative amount of gases released during the initial cycle is more than an order of magnitude larger for the liq-LIB than $\mathrm{SSB}$ cells. Moreover, we show that $\mathrm{SO}_{2}$ evolution may occur in lithium thiophosphatebased SSBs, its origin being related to the chemical reaction between $\mathrm{O}_{2}$, probably ${ }^{1} \mathrm{O}_{2}$, and the solid electrolyte.

In a wider context, our work broadens the picture of the implications of gas evolution in LIBs. From an application perspective, gassing of SSBs appears to be less critical 
than for liq-LIBs, since far less gaseous species are generated during cycling. However, the effect that solid electrolytes and especially surface-modified active materials can have on the gassing behavior calls for future studies to explore the complex interplay between interface/interphase formation and impedance buildup, among others.

\section{Associated Content}

Supporting Information

The Supporting Information is available free of charge on the ACS Publications website. Additional results from acid titration measurements and from DEMS for the liq-LIB and SSB cells.

\section{Author Information}

Corresponding Authors

*Phone: +49 721 60828907; Email: florian.strauss@kit.edu

*Phone: +49 721 60828827; Email: torsten.brezesinski@kit.edu

\section{ORCID}

Florian Strauss: 0000-0001-5817-6349

Jun Hao Teo: 0000-0002-0343-669X

Toru Hatsukade: 0000-0001-9016-0929

Jürgen Janek: 0000-0002-9221-4756

Torsten Brezesinski: 0000-0002-4336-263X

\section{Present Address}

A.S.: Carl Zeiss AG, Carl-Zeiss-Strasse 22, 73447 Oberkochen, Germany.

T.Ba.: VARTA AG, Alfred-Krupp-Strasse 9, 73479 Ellwangen, Germany.

T.H.: Argonne National Laboratory, 9700 South Cass Avenue, Lemont, IL 60439, USA.

\section{Notes}

The authors declare no competing financial interest. F.S. and J.H.T. contributed equally to this work.

\section{Acknowledgments}

This study is part of the projects being funded within the BASF International Network for Batteries and Electrochemistry. The authors also acknowledge the Federal Ministry of Education \& Research (BMBF) for funding within the project ARTEMYS (03XP0114J). 


\section{References}

(1) Larcher, D.; Tarascon, J.-M. Towards Greener and More Sustainable Batteries for Electrical Energy Storage. Nat. Chem. 2015, 7, 19-29.

(2) Myung, S.-T.; Maglia, F.; Park, K.-J.; Yoon, C. S.; Lamp, P.; Kim, S.-J.; Sun, Y.K. Nickel-Rich Layered Cathode Materials for Automotive Lithium-Ion Batteries: Achievements and Perspectives. ACS Energy Lett. 2017, 2, 196-223.

(3) Kong, W.; Li, H.; Huang, X.; Chen, L. Gas Evolution Behaviors for Several Cathode Materials in Lithium-Ion Batteries. J. Power Sources 2005, 142, 285-291.

(4) Imhof, R. Novak, P. Oxidative Electrolyte Solvent Degradation in Lithium-Ion Batteries: An In Situ Differential Electrochemical Mass Spectrometry Investigation. J. Electrochem. Soc. 1999, 146, 1702-1706.

(5) Jung, R.; Metzger, M.; Maglia, F.; Stinner, C.; Gasteiger, H. Chemical vs. Electrochemical Electrolyte Oxidation on NMC111, NMC622, NMC811, LNMO, and Conductive Carbon. J. Phys. Chem. Lett. 2017, 8, 4820-4825.

(6) Metzger, M.; Strehle, B.; Solchenbach, S.; Gasteiger, H. A. Origin of $\mathrm{H}_{2}$ Evolution in LIBs: $\mathrm{H}_{2} \mathrm{O}$ Reduction vs. Electrolyte Oxidation. J. Electrochem. Soc. 2016, 163, A798-A809.

(7) Berkes, B. B.; Schiele, A.; Sommer, H.; Brezesinski, T.; Janek, J. On the Gassing Behavior of Lithium-Ion Batteries with NCM523 Cathodes. J. Solid State Electrochem. 2016, 20, 2961-2967.

(8) Jung, R.; Metzger, M.; Maglia, F.; Stinner, C.; Gasteiger, H. A. Oxygen Release and Its Effect on the Cycling Stability of $\mathrm{LiNi}_{x} \mathrm{Mn}_{y} \mathrm{Co}_{z} \mathrm{O}_{2}(\mathrm{NMC})$ Cathode Materials for Li-Ion Batteries. J. Electrochem. Soc. 2017, 164, A1361-A1377.

(9) Renfrew, S. E.; McCloskey, B. D. Residual Lithium Carbonate Predominantly Accounts for First Cycle $\mathrm{CO}_{2}$ and $\mathrm{CO}$ Outgassing of Li-Stoichiometric and $\mathrm{Li}$ Rich Layered Transition Metal Oxides. J. Am. Chem. Soc. 2017, 139, 17853-17860.

(10) Bartsch, T.; Strauss, F.; Hatsukade, T.; Schiele, A.; Kim, A.-Y.; Hartmann, P.; Janek, J.; Brezesinski, T. Gas Evolution in All-Solid-State Battery Cells. ACS Energy Lett. 2018, 3, 2539-2543.

(11) Kim, A.-Y.; Strauss, F.; Bartsch, T.; Teo, J. H.; Hatsukade, T.; Mazilkin, A.; Janek, J.; Hartmann, P.; Brezesinski, T. Stabilizing Effect of a Hybrid Surface Coating on a Ni-Rich NCM Cathode Material in All-Solid-State Batteries. Chem. Mater. 2019, 31, 9664-9672.

(12) Hatsukade, T.; Schiele, A.; Hartmann, P.; Brezesinski, T.; Janek, J. Origin of Carbon Dioxide Evolved during Cycling of Nickel-Rich Layered NCM Cathodes. ACS Appl. Mater. Interfaces 2018, 10, 38892-38899.

(13) Berkes, B. B.; Jozwiuk, A.; Sommer, H.; Brezesinski, T.; Janek, J. Simultaneous Acquisition of Differential Electrochemical Mass Spectrometry and Infrared 
Spectroscopy Data for In Situ Characterization of Gas Evolution Reactions in Lithium-Ion Batteries. Electrochem. Commun. 2015, 60, 64-69.

(14) Berkes, B. B.; Jozwiuk, A.; Vračar, M.; Sommer, H.; Brezesinski, T.; Janek, J. Online Continuous Flow Differential Electrochemical Mass Spectrometry with a Realistic Battery Setup for High-Precision, Long-Term Cycling Tests. Anal. Chem. 2015, 87, 5878-5883.

(15) Mahne, N.; Renfrew, S. E.; McCloskey, B. D.; Freunberger, S. A. Electrochemical Oxidation of Lithium Carbonate Generates Singlet Oxygen. Angew. Chem. Int. Ed. 2018, 57, 5529-5533.

(16) Lux, S.; Baldauf-Sommerbauer, G.; Siebenhofer, M. Hydrogenation of Inorganic Metal Carbonates: A Review on Its Potential for Carbon Dioxide Utilization and Emission Reduction. ChemSusChem 2018, 11, 3357-3375.

(17) Jung, R.; Metzger, M.; Maglia, F.; Stinner, C.; Gasteiger, H. A. Oxygen Release and Its Effect on the Cycling Stability of $\mathrm{LiNix}_{x} \mathrm{Mn}_{y} \mathrm{Co}_{2} \mathrm{O}_{2}(\mathrm{NMC})$ Cathode Materials for Li-Ion Batteries. J. Electrochem. Soc. 2017, 164, A1361-A1377.

(18) Bartsch, T.; Kim, A.-Y.; Strauss, F.; de Biasi, L.; Teo, J. H.; Janek, J.; Hartmann, P.; Brezesinski, T. Indirect State-of-Charge Determination of All-Solid-State Battery Cells by X-Ray Diffraction. Chem. Commun. 2019, 55, 11223-11226.

(19) Strauss, F.; Bartsch, T.; de Biasi, L.; Kim, A.-Y.; Janek, J.; Hartmann, P.; Brezesinski, T. Impact of Cathode Material Particle Size on the Capacity of BulkType All-Solid-State Batteries. ACS Energy Lett. 2018, 3, 992-996.

(20) Chen, K.; Shinjo, S.; Sakuda, A.; Yamamoto, K.; Uchiyama, T.; Kuratani, K.; Takeuchi, T.; Orikasa, Y.; Hayashi, A.; Tatsumisago, M.; Kimura, Y.; Nakamura, T.; Amezawa, K.; Uchimoto, Y. Morphological Effect on Reaction Distribution Influenced by Binder Materials in Composite Electrodes for Sheet-Type All-SolidState Lithium-Ion Batteries with the Sulfide-Based Solid Electrolyte. J. Phys. Chem. C 2019, 123, 3292-3298.

(21) Koerver, R.; Aygün, I.; Leichtweiß, T.; Dietrich, C.; Zhang, W.; Binder, J. O.; Hartmann, P.; Zeier, W. G.; Janek, J. Capacity Fade in Solid-State Batteries: Interphase Formation and Chemomechanical Processes in Nickel-Rich Layered Oxide Cathodes and Lithium Thiophosphate Solid Electrolytes. Chem. Mater. 2017, 29, 5574-5582.

(22) Strauss, F.; Stepien, D.; Maibach, J.; Pfaffmann, L.; Indris, S.; Hartmann, P.; Brezesinski, T. Influence of Electronically Conductive Additives on the Cycling Performance of Argyrodite-Based All-Solid-State Batteries. RSC Adv. 2020, 10, 1114-1119.

(23) Auvergniot, J.; Cassel, A.; Ledeuil, J.-B.; Viallet, V.; Seznec, V.; Dedryvère, R. Interface Stability of Argyrodite $\mathrm{Li}_{6} \mathrm{PS}_{5} \mathrm{Cl}$ toward $\mathrm{LiCoO}_{2}$, $\mathrm{LiNi}_{1 / 3} \mathrm{Co}_{1 / 3} \mathrm{Mn}_{1 / 3} \mathrm{O}_{2}$, and $\mathrm{LiMn}_{2} \mathrm{O}_{4}$ in Bulk All-Solid-State Batteries. Chem. Mater. 2017, 29, 3883-3890.

(24) Walther, F.; Koerver, R.; Fuchs, T.; Ohno, S.; Sann, J.; Rohnke, M.; Zeier, W. G.; Janek, J. Visualization of the Interfacial Decomposition of Composite 
Cathodes in Argyrodite-Based All-Solid-State Batteries Using Time-of-Flight Secondary-Ion Mass Spectrometry. Chem. Mater. 2019, 31, 3745-3755.

(25) Freiberg, A. T.; Roos, M. K.; Wandt, J.; de Vivie-Riedle, R.; Gasteiger, H. A. Singlet Oxygen Reactivity with Carbonate Solvents Used for Li-lon Battery Electrolytes. J. Phys. Chem. A 2018, 122, 8828-8839.

(26) Wandt, J.; Freiberg, A. T. S.; Ogrodnik, A.; Gasteiger, H. A. Singlet Oxygen Evolution from Layered Transition Metal Oxide Cathode Materials and Its Implications for Lithium-Ion Batteries. Mater. Today 2018, 21, 825-833.

(27) Sasaki, I.; Komori, T.; Honda, K.; Hibino, J. Enhancement of Rate Capability for All-Solid-State Batteries Using Surface Oxidized Sulfide Solid Electrolyte. Electrochem. Soc. AiMES 2018 Meeting, Cancun, Mexico.

(28) Richards, W. D.; Miara, L. J.; Wang, Y.; Kim, J. C.; Ceder, G. Interface Stability in Solid-State Batteries. Chem. Mater. 2016, 28, 266-273.

(29) Zhu, Y.; He, X.; Mo, Y. Origin of Outstanding Stability in the Lithium Solid Electrolyte Materials: Insights from Thermodynamic Analyses Based on FirstPrinciples Calculations. ACS Appl. Mater. Interfaces 2015, 7, 23685-23693.

(30) Jung, R.; Strobl, P.; Maglia, F.; Stinner, C.; Gasteiger, H. A. Temperature Dependence of Oxygen Release from LiNio.6 $\mathrm{Mno}_{2 .} \mathrm{Co}_{0.2} \mathrm{O}_{2}$ (NMC622) Cathode Materials for Li-Ion Batteries. J. Electrochem. Soc. 2018, 165, A2869-A2879. 